8) and some of the longest schemes have very few training opportunities in the subject. Many posts seem to have been used very regularly since the time they were established, although some are used only occasionally. On average, posts have been vacant on a one year in four basis. A total of 185 trainees have received or are receiving training. Eighty-one are still trainees, of the 100 known to have taken up consultant posts, 48 are career psychogeriatricians, seven have a 'specialist interest' in old age psychiatry and 45 are general psychiatrists. Very few trainees appear to have had experience in more than one post offering experience in old age.

\section{Comment}

We believe the information we have received is reasonably accurate but it will be much more satisfactory when manpower statistics for old age psychiatry are collected routinely and centrally: The findings are encouraging in that more posts have been created, and quite a lot seem to have been created in conjunction with the first JPAC review. The track record of longer established posts is that roughly half the trainees go on to become psychogeriatricians, the others become general psychiatrists. Only the Southampton post has produced psychogeriatricians for $100 \%$ of the available time.

It remains to be seen what yield will result from the 37 posts yet to see a trainee achieve consultant status. The present appointment system for senior registrars (when aspiring old age psychiatrists are not appointed separately) perhaps make it unlikely that each post will produce more than one psychogeriatrician per two trainees.

Thus even if all new consultant psychogeriatricians complete only one year of specialist training (and our information suggests that this is sadly the case) then 86 posts would yield only 43 consultants per annum even if they were all used. This is more than ten short of the number of consultant posts advertised during 1988. If serious career minded psychogeriatricians are to spend more than one year and preferably two years training in the specialty as is suggested (JCHPT, 1987 and below) then the yield of the present posts will fall accordingly. It clearly remains important that aspiring general psychiatrists who wish to spend a year in old age psychiatry be enabled to do so - in at least as great a propoportion as now. There is therefore an argument for a continued expansion of old age psychiatry training posts.

\section{References}

Blessed, G. (1986) Survey into the availability of higher specialist training in the psychiatry of old age. November 1985. Bulletin of the Royal College of Psychiatrists, 10, 88-89.

JoInt CommitteE on Higher PSychiatric Training (1987) Handbook. Paragraph 3.23, p 31-32.

JOLLEY, D. (1985) Further developments in psychogeriatrics in Britain. British Medical Journal, 290, 240.

- (1988a) Defining a clearer role for psychogeriatrics. Geriatric Medicine, July, 60-62.

- (1988b) England expects: Are we prepared? Bulletin of the Royal College of Psychiatrists, 12, 102-103.

- (1989) England expects - More than we can provide. Psychiatric Bulletin of the Royal College of Psychiatrists, 13, 248-249.

- \& HORTON, R (1986) Senior registrar posts in old age psychiatry. Bulletin of the Royal College of Psychiatrists, 10, 213-214.

WatTis, J. P. (1988) Geographical variations in the provision of psychiatric services for old people. Age and Ageing, 17, 171-180.

- \& ARIE, T. (1984) Further developments in psychogeriatrics in Britain. British Medical Journal, 289, 778.

\title{
Report of the Special Committee of Council on Psychiatric Practice and Training in British Multi-ethnic Society
}

The Special Committee, which was set up by Council in 1987 under the chairmanship of Professor Kenneth Rawnsley, has now produced a report. This was received by Council at its meeting on 16 June 1989, when it was decided to remit the report for consideration, comments and recommendations to all Sections, Divisions and other appropriate Committees of the College. Copies of the report and supporting appendices are available to members of the College without charge. Applications should be sent to Lynette Napper, Education Officer. 